\title{
A myeloablative conditioning regimen with fludarabine demonstrates good results in UCBT for 30 pediatric patients with hematologic malignancies, especially acute lymphoblastic leukemia
}

\author{
J. TONG, Z. SUN*, H. LIU, L. GENG, K. DING, X. WANG, C. ZHENG, B. TANG, X. ZHU, W. YAO, K. SONG, X. LIU \\ Department of Hematology, Anhui Provincial Hospital, Hefei, China \\ ${ }^{*}$ Correspondence: ziminsun@126.com
}

Received January 8, 2014 / Accepted February 26, 2014

\begin{abstract}
We retrospectively analyzed the safety and efficacy of a myeloablative conditioning regimen with fludarabine (FLU) in unrelated cord blood transplantation (UCBT) of 30 pediatric patients with hematologic malignancies. The conditioning regimen consisted of FLU, busulfan (BU) and cyclophosphamide (CY). All of the patients received Cyclosporine (CSA) and mycophenolate mofetil (MMF) as graft versus host disease (GVHD) prophylaxis. We achieved high engraftment rates (96.7\%) and rapid hematopoietic reconstitution. Acute GVHD occurred in 12 cases of the 29 engraftment patients (41.4\%), and 6 cases (20.7\%) were of grade III-IV. Chronic GVHD only occurred in 1 of 28 evaluable patients (3.6\%). Twenty-three patients (76.7\%) became infected, and 3 cases (10.0\%) died of severe infections. Cytomegalovirus (CMV) reactivation occurred in $70.0 \%$ of the patients, but no CMV diseases were observed, nor did any patients die of CMV infection. The cumulative incidence of relapse (6.7\%) was significantly reduced, and none of the acute lymphoblastic leukemia (ALL) patients relapsed. The 3-year overall survival (OS) and event-free survival (EFS) rates were $73.3 \%$ and $70.0 \%$, respectively. The 3 -year OS and EFS of the ALL patients was $75.0 \%$. This conditioning regimen demonstrates good results and security in UCBT, especially in acute lymphoblastic leukemia.
\end{abstract}

Key words: conditioning regimen, cord blood transplant, fludarabine, hematologic malignancies

Umbilical cord blood transplantation (UCBT) has increasingly been used as a therapeutic option for patients affected by many disorders of either hematologic or non-hematologic origin [1-3]. In comparison to bone marrow transplantation (BMT), UCBT offers the advantage of easier procurement with no risk for the donor. In addition, there are lower risks of transmitting infections and of developing both acute and chronic GVHD. Despite the lower incidence of acute and chronic GVHD in UCB transplant recipients, the risk of leukemia relapse is not increased $[4,5]$. UCBT allows also transplantation in the absence of full HLA compatibility in the donor/recipient pair. Moreover, UCBT from unrelated donors offers the advantage of rapid availability of cryopreserved cells, and the median time for a successful donor search is less than 1 month [6]. However, there are also some drawbacks with UCBT in comparison with BMT. The nucleated cells contained in umbilical cord blood constitute only $1 / 10$ of the number of nucleated cells in the peripheral blood stem cells or bone marrow. Additionally, the $\mathrm{T}$ and $\mathrm{B}$ lymphocytes contained in umbilical cord blood are in their naïve state [7]. The limited number of cells and low immunogenicity of the nucleated cells could lead to the high incidence of engraftment failure and might slow hematopoietic and immune reconstitution, which could result in the high incidence of early opportunistic infections $[8,9]$.

How to increase the UCBT engraftment rate and reduce the incidence of infections is an important area of study. Researchers have attempted to solve both of these problems through a variety of methods, including increasing the nucleated cell count and CD34 positive cell count and adjusting the conditioning regimen. BU and $\mathrm{CY}$ are the classic drugs contained used in myeloablative conditioning regimens for multiple types of hematopoietic stem cell transplantations (HSCTs). However, UCBT must be applied with a stronger immune inhibition in order to achieve engraftment. There is currently no standardized conditioning regimen for UCBT, and the main program is based on TBI or chemotherapy [10]. The conditioning regimen based on TBI often results in a high and relatively stable 
engraftment rate. The engraftment rate has always been greater than $90 \%$ when using the TBI-based conditioning regimen to treat adult patients with hematologic malignancies at the University of Tokyo, Japan [11]. We have also obtained very good results with UCBT in adult patients using a TBI-based conditioning regimen (TBI + Ara-C $+\mathrm{CY})$, and the engraftment rate has approached $100 \%$ [12]. TBI can affect the growth of children and we do not use TBI as the conditioning regimen in pediatric patients. Almost all of the chemotherapy programs contain ATG and other strong immunosuppressive agents to prevent engraftment failure and to alleviate GVHD, but these regimens also delay immune reconstitution, increase the risk of severe infection and can reduce the graft-versus-leukemia effect (GVL) and increase the relapse rate [13]. As previously mentioned, the number of nucleated cells in the graft is limited, and $\mathrm{T}$ and $\mathrm{B}$ lymphocytes are in their naïve state. Therefore,

Table 1. Characteristics of UCBT patients and grafts

\begin{tabular}{|c|c|}
\hline Parameter & numerical value \\
\hline Overall, NO. & 30 \\
\hline \multicolumn{2}{|l|}{ Age (years) } \\
\hline Median & 8 \\
\hline Range & $3 \sim 14$ \\
\hline \multicolumn{2}{|l|}{ Body weight, kg } \\
\hline Median & 28 \\
\hline range & $12 \sim 44$ \\
\hline \multicolumn{2}{|l|}{ Gender, NO. (\%) } \\
\hline Male & $16(53.3 \%)$ \\
\hline female & $14(46.7 \%)$ \\
\hline \multicolumn{2}{|l|}{ Diseases, NO. (\%) } \\
\hline ALL & $16(53.3 \%)$ \\
\hline ANLL & $14(46.7 \%)$ \\
\hline \multicolumn{2}{|c|}{ Risk of underlying diseases, NO. (\%) } \\
\hline High & $26(86.7 \%)$ \\
\hline progressive & $12(40.0 \%)$ \\
\hline \multicolumn{2}{|c|}{ Donor-recipient sex match, NO. (\%) } \\
\hline Male-male & $7(23.3 \%)$ \\
\hline Male-female & $11(36.7 \%)$ \\
\hline Female-male & $9(30.0 \%)$ \\
\hline Female-female & $3(10.0 \%)$ \\
\hline \multicolumn{2}{|c|}{ HLA compatibility, NO. (\%) } \\
\hline 6 of 6 & $5(16.7 \%)$ \\
\hline 5 of 6 & $20(66.7 \%)$ \\
\hline 4 of 6 & $5(16.7 \%)$ \\
\hline \multicolumn{2}{|c|}{ ABO blood group mismatch, NO. (\%) } \\
\hline Major & $6(20.0 \%)$ \\
\hline Minor & $9(30.0 \%)$ \\
\hline Major and Minor & $2(6.7 \%)$ \\
\hline None & $13(43.3 \%)$ \\
\hline \multicolumn{2}{|c|}{ Nucleated cells infused, $\times 10^{7} / \mathrm{kg}$} \\
\hline Median & 5.6 \\
\hline Range & $3.2 \sim 9.6$ \\
\hline \multicolumn{2}{|c|}{ No. of CD34+cells infused, $\times 10^{5} / \mathrm{kg}$} \\
\hline Median & 3.1 \\
\hline Range & $1.7 \sim 5.2$ \\
\hline
\end{tabular}

some transplant centers have attempted to use conditioning regimens without ATG in UCBT $[14,15]$. FLU is a potent immunosuppressive agent with limited non-hematologic cytotoxic properties, which have resulted in its broad and effective use in reduced-intensity conditioning regimens $[16,17]$. We used the effects of the engraftment-promoting effects of FLU and combined it with the standard BU/CY regimen to form a new myeloablative conditioning regimen of FLU $+\mathrm{BU}+\mathrm{CY}$ in UCBT resulted in a high engraftment rate, low incidence of infection and good survival.

Here, we present the clinical outcomes of 30 pediatric patients with standard or high-risk hematological malignancies who received UCBT, with the conditioning regimen containing chemotherapy alone (FLU + BU + CY) and without ATG from unrelated donors.

\section{Patients and methods}

Patient and donor characteristics. Between August 2010 and August 2011, 30 consecutive pediatric patients with hematological malignancies, who had no HLA-compatible related donors or unrelated bone marrow donors and who were eligible for UCBT from unrelated donors, were treated at the affiliated Anhui Provincial Hospital of Anhui Medical University. The patient characteristics are shown in Table 1. The performance status (ECOG score) in 24 cases ranged from 0 to 1 , and the scores in other 6 cases were all 3 . There were 26 patients $(86.7 \%)$ with high-risk or refractory disease and 12 cases $(40.0 \%)$ with disease progression, and the judgment criterion of high-risk, refractory and disease progression are consistent with the reported literature [18]. All of the patients were fully informed of their disease status and treatment options, and the transplant protocol was approved by the Anhui Medical University Institutional Review Board.

CB unit selection and management. The HLA-A and HLA-B antigens were typed using standard serological techniques. HLA-DRB1 alleles were typed using high-resolution DNA techniques. Cord blood units were found through the Chinese Cord Blood Bank Network. Cord blood units matched at 4 or more of 6 HLA loci were selected. Preferred cord blood units contained a minimal cell count of $3.0 \times 10^{7}$ nucleated cells $/ \mathrm{kg}$ and $1.2 \times 10^{5} \mathrm{CD} 34$ positive cells $/ \mathrm{kg}$ before freezing. Additionally, $\mathrm{ABO}$ compatibility and the year of storage were also considered. All of the CB units tested negative for human immunodeficiency virus (HIV), hepatitis B and C viruses (HBV, $\mathrm{HCV}$ ) and human T cell lymphotropic virus type I. All of the $\mathrm{CB}$ units and mothers were negative for the immunoglobulin $\mathrm{M}$ antibody to cytomegalovirus (CMV).

Conditioning regimen. The myeloablative conditioning regimen consisted of FLU (Baxter Oncology GmbH, Halle, Germany), BU (Ben Venue, Ohio, USA) and CY (Baxter Oncology GmbH, Halle, Germany). FLU (30 mg/m²) was administered intravenously as a single daily dose on days -8 to -5 (total dose $\left.120 \mathrm{mg} / \mathrm{m}^{2}\right)$, BU $(0.8 \mathrm{mg} / \mathrm{kg})$ was administered intravenously every 6 hours on days -7 to -4 (total dose 
$12.8 \mathrm{mg} / \mathrm{kg}^{2}$ ), and CY was administered intravenously over 2 hours at a dose of $60 \mathrm{mg} / \mathrm{kg}$ once daily on days -3 and -2 (total dose $120 \mathrm{mg} / \mathrm{kg}$ ). Twenty-four hours after the completion of conditioning, the patients received UCBT.

GVHD prophylaxis. All of the patients received CSA (Novartis, Stein, Switzerland) and MMF (Roche, Basel, Switzerland) as GVHD prophylaxis. I.v. CSA was started (3 $\mathrm{mg} / \mathrm{kg} /$ day) on day -1 and was continued until the patients were able to take CSA orally, with target trough levels of 150$250 \mathrm{ng} / \mathrm{mL}$ for at least 1 month. CSA was discontinued on day 180 or earlier if feasible. MMF was administered at a total dose of $30 \mathrm{mg} / \mathrm{kg}$ orally, 3-4 times per day from day +1 to +35 . The rapidity of tapering was based on the presence or absence of GVHD, infectious disease and relapse risk.

Supportive care. The patients were hospitalized in single rooms ventilated with high-efficiency particulate air filtration systems. All of the patients received G-CSF by intravenous infusion starting on day 6 , until the absolute neutrophil count (ANC) exceeded $2 \times 10^{9} / \mathrm{L}$. Phenytoin sodium was used once per day before the infusion of BU to prevent epilepsy, and heparin and prostaglandin E1 were used to prevent veno-occlusive disease (VOD). Mesna was administered after cyclophosphamide to prevent hemorrhagic cystitis (HC). All of the blood products were irradiated and leukocyte-depleted. The supportive care regimen, including CMV prophylaxis, infection surveillance and prophylaxis, has been previously reported [19].

Definitions of engraftment. Myeloid engraftment was defined as the 1st day during which the absolute neutrophil count (ANC) exceeded $0.5 \times 10^{9} / \mathrm{L}$ for 3 consecutive days. Platelet engraftment was defined as the 1st day on which the platelet count exceeded $20 \times 10^{9} / \mathrm{L}$ without transfusion support for 7 consecutive days. Chimeric analysis of peripheral blood or bone marrow was performed using quantitative PCR for microsatellite DNA markers. Failure to engraft was defined as lack of evidence of hematopoietic recovery (ANC $<0.5 \times$ $10^{9} / \mathrm{L}$ and platelet count $<20 \times 10^{9} / \mathrm{L}$ ) by day +30 and less than $5 \%$ marrow reconstitution of donor origin detected by short tandem repeat-polymerase chain reaction (STR-PCR).

Statistical analysis. The statistical analyses were performed using SPSS statistical software, version 19.0. The results are reported as median values with specific ranges of data sets. An independent sample t-test was used to compare the sets of measurement data, and the $\chi^{2}$ test was used to compare the rates. Both acute GVHD and chronic GVHD were graded according to the previously published Seattle criteria [20]. Relapse was defined by morphologic evidence of disease in peripheral blood, bone marrow or extramedullary sites. Treatment-related mortality (TRM) was defined as death from all causes except for relapse. Overall survival (OS) was defined as the time from UCBT to death or to the last observation. Event-free survival (EFS) was defined as the time from UCBT to relapse, death or the last observation. The probabilities of neutrophil and platelet engraftment, acute and chronic GVHD, TRM and relapse, OS and EFS were estimated using the Kaplan-Meier method, and the 2-tailed log-rank test was used to compare survival curves. Differences of $\mathrm{P}<0.05$ were considered significant.

\section{Results}

Characteristics of the patients and umbilical cord blood. The characteristics of the 30 pediatric patients and the cord blood units are presented in Table 1 . All of the patients received a single cord blood unit. The median number of cryopreserved nucleated cells of cord blood was $5.6(3.2-9.6) \times 10^{7} / \mathrm{kg}$ of patient body weight, and the median number of cryopreserved CD34 positive cells was $3.1(1.7-5.2) \times 10^{5} / \mathrm{kg}$. T cell depletion was not performed.

Hematopoietic recovery. Chimeric analysis was performed using peripheral blood on days 7, 14 and 21 and using bone marrow on day 28 in all of the patients. All but 1 patient acquired myeloid reconstitution, and all exhibited full donor chimerism within 3 weeks after UCBT. The cumulative incidence of neutrophil engraftment was $96.7 \%$. Twenty-nine patients exhibited neutrophil engraftment at a median time of 16 (12-30) days, and all of the patients exhibited platelet engraftment at a median interval of 33 (14-83) days. The only patient who experienced primary engraftment failure was a 12year-old girl diagnosed with acute monocytic leukemia. This patient underwent a 2nd haploidentical transplant from her mother after conditioning with a FLU-based reduced-intensity regimen on day 42 after UCBT. She achieved hematopoietic recovery and was disease-free for 35 months at the end of the follow-up.

Pre-engraftment syndrome. Nineteen cases (63.3\%) exhibited pre-engraftment syndrome (PES). All of these cases exhibited fever and skin rash, and 9 cases (30.0\%) were associated with diarrhea. No patients suffered from jaundice. Fifteen cases improved after treatment with methylprednisolone and after adjustment of immunosuppressive agents, and 4 patients developed grade IV acute GVHD and ultimately died.

Acute and chronic GVHD. Twelve of the 29 engraftment patients (41.4\%) who could be evaluated developed acute GVHD (grade I in 3 patients, grade II in 3 patients, grade III in 2 patients and grade IV in 4 patients), and the cumulative incidence of grade III to IV acute GVHD was $20.7 \%$ (6 of 29). The organ involvement in the acute GVHD cases is shown in Table 2 . One of the 28 patients (3.6\%) who could be evaluated

Table 2. Acute GVHD, Clinical Stage for 29 engraftment patients

\begin{tabular}{lcccc}
\hline \multicolumn{5}{c}{ Organ involvement } \\
\hline NO. Patients (\%) & Grade & Skin (NO.) & Liver (NO.) & GI (NO.) \\
\hline $17(58.6 \%)$ & 0 & 0 & 0 & 0 \\
$3(10.3 \%)$ & I & 3 & 0 & 0 \\
$3(10.3 \%)$ & II & 2 & 1 & 0 \\
$2(6.9 \%)$ & III & 2 & 0 & 2 \\
$4(13.8 \%)$ & IV & 4 & 2 & 4 \\
\hline
\end{tabular}

GI, gastrointestinal GVHD; GVHD, graft versus host disease 


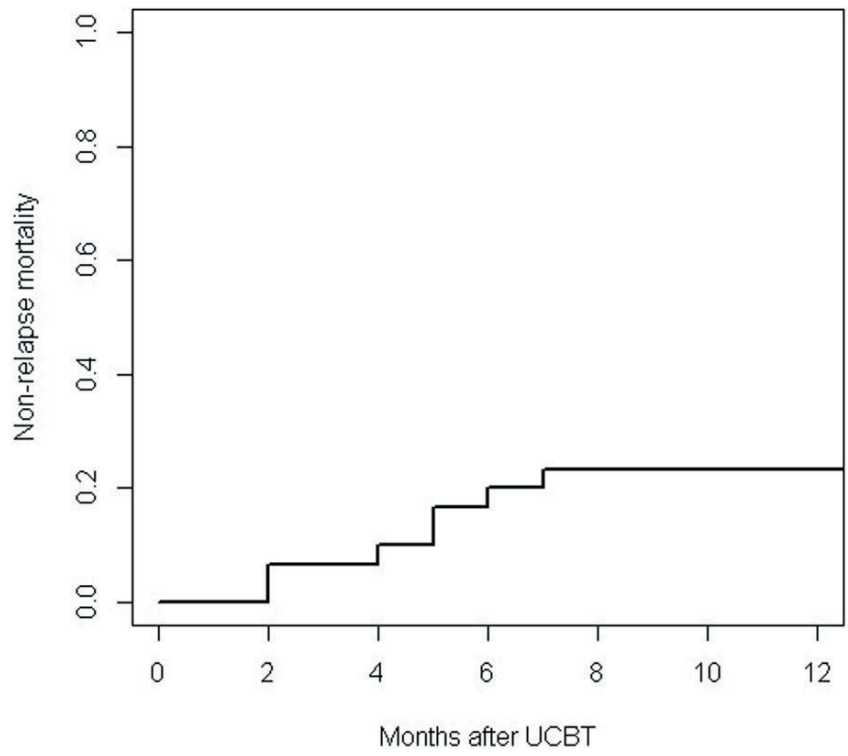

Figure 1. The cumulative incidences of NRM among the UCBT recipients.

developed chronic GVHD, which was limited to the skin. Cases of grade I-II acute GVHD and chronic GVHD cases were well controlled by CSA and methylprednisolone. The patients with grade III acute GVHD were controlled after methylprednisolone and CD25 monoclonal antibody (CD25 $\mathrm{mAb}$ ). Four cases of grade IV acute GVHD patients remained unaffected by treatment with methylprednisolone, CD25 $\mathrm{mAb}$, mesenchymal stem cells and tumor necrosis factor- $\alpha$ and ultimately died.

Infection. Twenty-three patients $(76.7 \%)$ suffered infections of varying types and degrees within 180 days after UCBT. Three patients (10.0\%) died of severe lung infections, which were clinically diagnosed as fungal infections, at 4 months, 5 months and 6 months, respectively, after CBT. Blood cultures and drug sensitivity tests were conducted in those patients suspected to have infections. Bloodstream infections were detected in 3 cases (10.0\%), and the causative agents were Staphylococcus albus, Escherichia coli and Streptococcus viridans;

Table 3. Organ toxicity according to Bearman's criteria

\begin{tabular}{lcc}
\hline & Grade I and II & Grade III and IV \\
\hline Gut & 22 & 2 \\
Mucosa & 15 & 1 \\
Bladder & 5 & 0 \\
Liver & 7 & 1 \\
Kidneys & 2 & 0 \\
Heart & 4 & 0 \\
CNS & 1 & 0 \\
Lungs & 0 & 0 \\
\hline
\end{tabular}

FLU: fludarabine (FLU); BU: busulfan; CY: cyclophosphamide; CNS: central nervous system

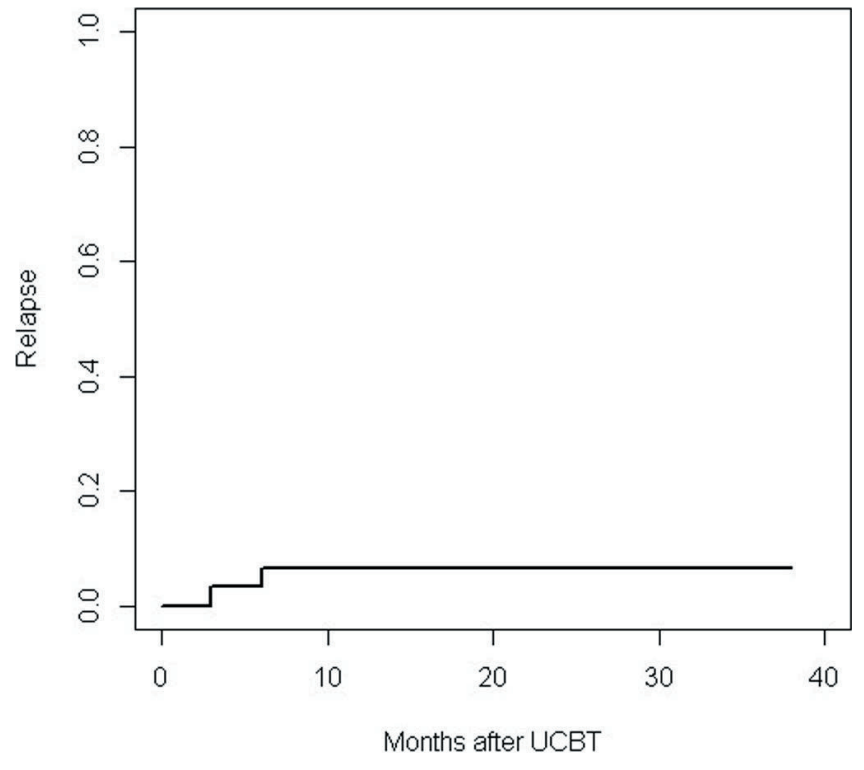

Figure 2. The cumulative incidence of relapse for the entire group.

the patients improved after anti-infection therapy. CMV reactivation occurred in $56.7 \%$ (17 of 30) of the patients between 18 and 139 days after UCBT. The copy numbers of CMV-DNA reached $10^{4}$ in 2 cases (6.7\%), $10^{3}$ in 5 cases (16.7\%), $10^{2}$ in 9 cases $(30.0 \%)$ and $10^{1}$ in 1 patient (3.3\%). CMV infection was controlled after treatment with ganciclovir and/or foscarnet, and the CMV-DNA tests became negative after a median time of 23 (range from 7 to 89) days. There were no CMV diseases, and no patients died of CMV infection.

Regimen-related toxicity (RRT). RRT was graded according to Bearman's criteria [23]. The incidence of total RRT were $86.7 \%(26 / 30)$, and III-IV RRT were $13.3 \%(4 / 30)$ of the patients. The gastrointestinal side effects were the most common toxicity $(80.0 \%, 24 / 30)$ and III-IV gastrointestinal side effects were $6.7 \%(2 / 30)$. The mucositis was also a very common toxicity $(55.8 \%, 16 / 30)$ and III-IV mucositis were $3.3 \%($ $1 / 30$ ). Hemorrhagic cystitis (HC) developed in 5 cases (16.7\%), all of which improved after hydration and other symptomatic treatment. No patients suffered VOD or interstitial pneumonia (IP) and there were one regimen-related death. Organ toxicities are summarized in table 3.

Non-relapse mortality. The cumulative incidences of NRM were $6.7 \% \pm 0.2 \%$ within 100 days and $23.3 \% \pm 0.6 \%$ within 1 year among the UCBT recipients (figure 1). The causes of NRM within 100 days were all acute GVHD, and the causes within 1 year were acute GVHD in 4 patients and pneumonia in 3 patients. The patients who suffered from NRM within 100 days and 1 year were all high-risk patients.

Relapse. Two patients with high-risk acute non-lymphocytic leukemia (ANLL) relapsed. The cumulative incidence of relapse at 2 years was $6.7 \% \pm 0.2 \%$ for the entire group (figure 2). The relapses originated from extramedullary sources, 
including 1 case from central nervous system leukemia (CNSL) at 3 months and the other from testis infiltration at 6 months after UCBT. The patient who relapsed with CNSL received intrathecal injections of chemotherapy drugs and achieved another CR. The other patient with the testis infiltration died with disease progression at 9 months after transplantation. No cases of acute lymphoblastic leukemia (ALL) relapsed, and no cases of standard-risk patients relapsed.

Survival. The median follow-up after transplantation for the 30 patients was 25 months (range 2-36), and it was 31 months (range 28-36) for the 22 (73.3\%) patients who were alive and disease-free with full donor chimerism. Out of the 30 patients, 8 died. One of these 8 patients died of disease progression, and 7 deaths were associated with non-relapse mortality (NRM). The cumulative mortality rate (CMR) was $26.7 \%(8 / 30)$.

Transplantation results for ALL. None of the 16 ALL patients relapsed despite all of them were high-risk patients. The risk factors of these patients are shown in Table 3. The median follow-up for these patients was 25 months (range $2-35$ ), and it was 31 months (range 28-35) for the 12 (75.0\%) patients who remained alive. Four patients died, including 2 cases of aGVHD and 2 cases of pneumonia, and the CMR was $25.0 \%(4 / 16)$. The cumulative OS and EFS rates at 3 years were both $75.0 \%$ (Figure 3).

\section{Discussion}

FLU is a novel purine nucleoside analogue which performs an immunosuppressive role, thereby creating an environment that promotes donor stem cell engraftment. The major pharmacodynamic effect of FLU on cellular metabolism is the disruption of DNA synthesis. Replication of the lagging DNA strand requires the synthesis of short RNA primers by DNA primase, to enable DNA synthesis to begin. Recent evidence suggests that DNA primase is inhibited by arabinofuranosyl2-fluoroadenine-adenosine triphosphate (2F-ara-ATP) [21], leading to the disruption of DNA synthesis. For acute lymphocytic leukemia induction and consolidation chemotherapy, FLU might require a larger dose, which can result in nervous system damage [22]. Therefore, FLU is rarely used for the chemotherapy in ALL. However, Flu indirectly but synergistically enhances BU-induced cytotoxicity by interfering with the repair of radiation therapy (XRT) - and alkylator-induced DNA damage [23].

Only 1 patient experienced engraftment failure, and the engraftment rate was $96.7 \%$. The patients who were successfully engrafted all reached full donor chimerism (FDC) within 21 days after UCBT. Neutrophil engraftment was achieved at a median time of 16 (12-30) days, and platelet engraftment was achieved within a median interval of 33 (14-83) days. These results were equivalent to or even better than many multicenter myeloablative HSCT regimens that have been reported. Ciurea SO [24] and his colleagues used an UCBT conditioning regimen consisting of melphalan, thiotepa,

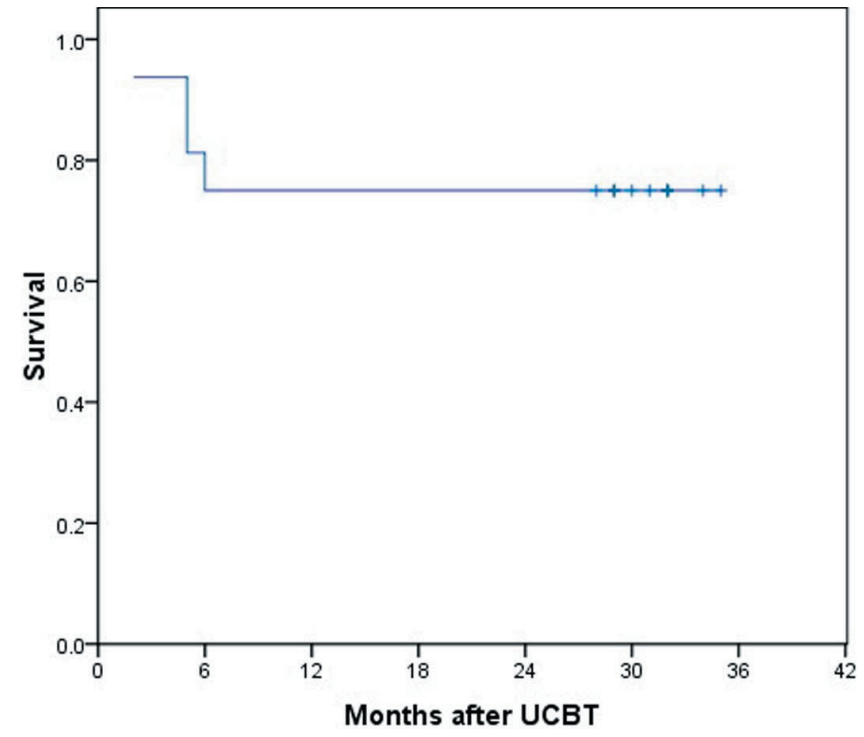

Figure 3. The cumulative OS and EFS rates for the entire group.

fludarabine and rabbit anti-thymocyte globulin (ATG). The authors achieved an engraftment rate of $91 \%$, and the median time to neutrophil engraftment was 22 days. Conditioning regimen without ATG can make the neutrophil and platelet engraftment become earlier.

The cumulative incidence of relapse at 2 years was $6.7 \%$, which was significantly lower than in related reports. Bachanova V [25] reported 143 cases of UCBT in patients with acute lymphoblastic leukemia. Patients exhibited a relapse rate of $16-30 \%$ at 2 years. And we had no ALL patients relapsed after UCBT, which could have been associated with the use of fludarabine in our study. Daly A [26] also achieved excellent outcomes in the treatment of 44 high-risk or advanced ALL patients after UCBT with the conditioning regimen of fludarabine + busulfan + total body irradiation. The relapse rate was $14 \%$, the 5 -year progression-free survival was $56.7 \%$, and the 5-year overall survival was $66.0 \%$. We also achieved good survival with this conditioning regimen. The cumulative OS and EFS rates at 3 years were $73.3 \%$ and $70.0 \%$, respectively, for all of the patients and $75.0 \%$ for the ALL patients. In a recent report from COBLT on children with hematologic malignancies, the 2-year OS was $50 \%$ and the 2 -year EFS rates were $30 \%$ to $40 \%$ [28-30].

Table 4. Risk factors of 16 ALL patients

\begin{tabular}{lc}
\hline Risk factors & numerical value \\
\hline WBC $>100 \times 10^{9} / \mathrm{L}$ & 3 \\
BCR/ABL $(\mathrm{P} 190)$ & 6 \\
BCR/ABL(P210) & 4 \\
E2A/PBX1 & 2 \\
HOX-11 & 1 \\
\hline
\end{tabular}


Nineteen cases (63.3\%) developed PES, and 4 patients (13.3\%) developed into grade IV acute GVHD and ultimately died. The incidence of PES was higher than in other reports. Frangoul [31] and Patel [32] reported that $31 \%$ of double-unit CBT recipients and $20 \%$ of myeloablative single-unit CBT recipients, respectively, fulfilled the PES criteria. The most common symptoms of PES are fever, rash, diarrhea and jaundice, and all of these symptoms must be identified with early infection after transplantation. Because 13 patients exhibited early infection with PES, there might have been delays in PES treatment in some patients. If PES is not identified and treated in a timely manner, it can develop into acute GVHD. Therefore, we must be alert to the development of PES and provide timely treatment in the future to reduce the occurrence of severe acute GVHD. Another study [33] reported that myeloablative conditioning and younger age were risk factors for developing PES. The high incidence of PES in our study might have been related to the myeloablative program and predominance of pediatric patients.

Acute GVHD, especially gastrointestinal GVHD (GIGVHD), remains a difficult problem. The cumulative incidence of grades I to IV acute GVHD (41.4\%) was similar in our study to that in other reports, whereas the incidence of grades III-IV (20.7\%) was slightly higher than in other reports. Borje S [22] used clofarabine \pm fludarabine with once daily busulfan intravenously as the conditioning regimen for advanced myeloid leukemia and MDS. The incidence of grade I-IV acute GVHD was $49 \%(25 / 51)$, and the incidence of grades III-IV aGVHD was $8 \%(4 / 51)$. The increase of III to IV acute GVHD may be related to the high incidence of PES and the absence of ATG in our study. If PES can be treated more effectively and in a more timely manner, the grade III to IV acute GVHD might have been decreased to a large extent. However, the incidence of chronic GVHD (3.6\%) was much lower than in other related reports, and no patients developed extensive chronic GVHD; thus, the patients' quality of life was significantly improved. Ciurea SO [24] reported that the incidences of acute GVHD and chronic GVHD were $53 \%$ and $34 \%$, respectively.

Less post-transplant infection rates than those of other reports might be associated with the absence of ATG and rapid recovery of the neutrophil count. Twenty-three patients (76.7\%) became infected within 180 days after UCBT, and 3 cases (10.0\%) died of severe lung infections. Saavedra S [34] reported that all of their patients (100\%) experienced at least 1 infectious episode, and $66 \%$ of them suffered from severe infections. Bloodstream infections occurred in $10 \%$ of the patients in our study, and the rate of CMV reactivation in the overall series was $56.7 \%$ ( 17 of 30 ), which was similar to the reports in the literature $[35,36]$, but the number of CMV-DNA copies decreased significantly compared to that in other reports. None of the patients developed CMV disease, whereas Milano $\mathrm{F}$ [36] reported an incidence of CMV disease of 5-28\%. Sauter C [14] reported that UCBT without ATG was associated with prompt $\mathrm{T}$ cell recovery, which might have led to the reduction in CMV infection.
In summary, we observed that the prominent features of this conditioning regimen were the high engraftment rate, rapid myeloid reconstruction and low incidence of infection. Although there were many patients with high-risk disease and disease progression, the study was characterized by a low relapse rate and good survival. None of the ALL patients relapsed after UCBT, indicating that this conditioning regimen could be applied in more patients with ALL. We must be alert to the development of PES and provide timely treatment to reduce the occurrence of severe acute GVHD. Chronic GVHD was significantly reduced, resulting in improvements in the patients' quality of life. Further studies are under way to explore the mechanism of this program.

Acknowledgements: This study was supported by the Anhui Provincial University Scientific Research Projects (KJ2013Z123), National Natural Science Funds of China (81250001), the Twelfth Five-year Science and Technology Projects in Anhui Province (11010402164), Anhui Province Science and Technology Leader of Scientific Research Funds and Anhui Provincial'115'Industrial Innovation Program (2009).

\section{References}

[1] BENITO AI, DIAZ MA, GONZALEZ-VICENT M, SEVILLA J, MADERO L. Hematopoietic stem cell transplantation using umbilical cord blood progenitors: review of current clinical results. Bone Marrow Transplant 2004; 33: 675-690. http:// dx.doi.org/10.1038/sj.bmt.1704405

[2] COHEN Y, NAGLER A. Umbilical cord blood transplantation-how, when, and for whom? Blood Rev 2004; 18: 167-179. http://dx.doi.org/10.1016/S0268-960X(03)00064-X

[3] BROWN JA, BOUSSIOTIS VA. Umbilical cord blood transplantation: basic biology and clinical challenges to immune reconstitution. Clin Immunol 2008; 127: 286-297. http:// dx.doi.org/10.1016/j.clim.2008.02.008

[4] GUTMAN JA, LEISENRING W, APPELBAUM FR, WOOLFREY AE, DELANEY C. Low relapse without excessive transplant-related mortality following myeloablative cord blood transplantation for acute leukemia in complete remission: a matched cohort analysis. Biol Blood Marrow Transplant 2009; 15: 1122-1129. http://dx.doi.org/10.1016/ j.bbmt.2009.05.014

[5] BAEK HJ, KOOK H, HAN DK, HWANG TJ. Hematopoietic stem cell transplantation in children with leukemia: a single institution experience with respect to donors. J Korean Med Sci 2011; 26: 1548-1555. http://dx.doi.org/10.3346/ jkms.2011.26.12.1548

[6] BERTAINA A, BERNARDO ME, CANIGLIA M, VINTI L, GIORGIANI $G$ et al. Cord blood transplantation in children with haematological malignancies. Best Pract Res Clin Haematol 2010; 23: 189-196. http://dx.doi.org/10.1016/ j.beha.2010.06.005

[7] ROCHA V, LABOPIN M, SANZ G, ARCESE W, SCHWERDTFEGER R et al. Transplants of umbilical-cord blood or bone marrow from unrelated donors in adults with acute 
leukemia. N Engl J Med 2004; 351: 2276-2285. http://dx.doi. org/10.1056/NEJMoa041469

[8] TAKAHASHI S, ISEKI T, OOI J, TOMONARI A, TAKASUGI $\mathrm{K}$ et al. Single-institute comparative analysis of unrelated bone marrow transplantation and cord blood transplantation for adult patients with hematologic malignancies. Blood 2004; 104: 3813-3820. http://dx.doi.org/10.1182/blood-2004-03$\underline{1001}$

[9] TAKAHASHI S, OOI J, TOMONARI A, KONUMA T, TSUKADA $\mathrm{N}$ et al. Comparative single-institute analysis of cord blood transplantation from unrelated donors with bone marrow or peripheral blood stem-cell transplants from related donors in adult patients with hematologic malignancies after myeloablative conditioning regimen. Blood 2007; 109: 1322-1330. http://dx.doi.org/10.1182/blood-2006-04020172

[10] ORAN B, SHPALL E. Umbilical cord blood transplantation: a maturing technology. Hematology Am Soc Hematol Educ Program 2012; 2012: 215-222.

[11] SATO A, OOI J, TAKAHASHI S, TSUKADA N, KATO S et al. Unrelated cord blood transplantation after myeloablative conditioning in adults with advanced myelodysplastic syndromes. Bone Marrow Transplant 2011; 46: 257-261. http://dx.doi. org/10.1038/bmt.2010.91

[12] SUN ZM, LIU HL, GENG LQ, ZHOU CY, WANG XB et al. Unrelated umbilical cord blood transplantation with TBI/ Ara-c/CY non-ATG conditioning regimen for adults with hematologic malignancies. Zhonghua Yi Xue Za Zhi 2012; 92: 1660-1664.

[13] KOO HH, AHN HS. Umbilical cord blood transplantation. Korean J Pediatr 2012; 55: 219-223. http://dx.doi.org/10.3345/ kjp.2012.55.7.219

[14] SAUTER C, ABBOUD M, JIA X, HELLER G, GONZALES $\mathrm{AM}$ et al. Serious infection risk and immune recovery after double-unit cord blood transplantation without antithymocyte globulin. Biol Blood Marrow Transplant 2011; 17: 1460-1471. http://dx.doi.org/10.1016/j.bbmt.2011.02.001

[15] KISHI Y, KAMI M, MIYAKOSHI S, KANDA Y, MURASHIGE $\mathrm{N}$ et al. Early immune reaction after reducedintensity cord-blood transplantation for adult patients. Transplantation 2005; 80: 34-40. http://dx.doi.org/10.1097/01. TP.0000163289.20406.86

[16] CHEWNING JH, CASTRO-MALASPINA H, JAKUBOWSKI A, KERNAN NA, PAPADOPOULOS EB et al. Fludarabine-based conditioning secures engraftment of second hematopoietic stem cell allografts (HSCT) in the treatment of initial graft failure. Biol Blood Marrow Transplant 2007; 13: 1313-1323. http://dx.doi.org/10.1016/j.bbmt.2007.07.006

[17] BOLANOS-MEADE J, LUZNIK L, MUTH M, MATSUI WH, HUFF CA et al. Salvage transplantation for allograft failure using fludarabine and alemtuzumab as conditioning regimen. Bone Marrow Transplant 2009; 43: 477-480. http://dx.doi. org/10.1038/bmt.2008.353

[18.] HUANG XJ, WANG Y, LIU DH, XU LP, CHEN H et al. Modified donor lymphocyte infusion (DLI) for the prophylaxis of leukemia relapse after hematopoietic stem cell transplantation in patients with advanced leukemia--feasibility and safety study. J Clin Immunol 2008; 28: 390-397. http://dx.doi. org/10.1007/s10875-008-9193-4

[19] LIU HL, SUN ZM, GENG LQ, WANG XB, DING KY et al. Unrelated cord blood transplantation for newly diagnosed patients with severe acquired aplastic anemia using a reducedintensity conditioning: high graft rejection, but good survival. Bone Marrow Transplant 2012; 47: 1186-1190. http://dx.doi. org/10.1038/bmt.2011.251

[20] CHAMPLIN R, KHOURI I, KORNBLAU S, MOLLDREM J, GIRALT $S$ et al. Reinventing bone marrow transplantation: reducing toxicity using nonmyeloablative, preparative regimens and induction of graft versus-malignancy. Curr Opin Oncol 1999; 11: 87-95. http://dx.doi.org/10.1097/00001622199903000-00003

[21] CATAPANO CV, CHANDLER KB, FERNANDES DJ. Inhibition of primer RNA formation in CCRF-CEM leukemia cells by fludarabine triphosphate. Cancer Res 1991; 51: 1829-1835.

[22] ANDERSSON BS, VALDEZ BC, DE LIMA M, WANG X, THALL PF et al. Clofarabine \pm Fludarabine with Once Daily i.v. Busulfan as Pretransplant Conditioning Therapy for Advanced Myeloid Leukemia and MDS. Biol Blood Marrow Transplant 2011; 17: 893-900. http://dx.doi.org/10.1016/ j.bbmt.2010.09.022

[23] GANDHI V, PLUNKETT W. Cellular and clinical pharmacology of fludarabine. Clin Pharmacokinet 2002; 41: 93-103. http://dx.doi.org/10.2165/00003088-200241020-00002

[24] CIUREA SO, SALIBA RM, HAMERSCHLAK N, KARDUSS AURUETA AJ, BASSETT R et al. Fludarabine, melphalan, thiotepa and anti-thymocyte globulin conditioning for unrelated cord blood transplant. Leuk Lymphoma 2012; 53: 901-906. http://dx.doi.org/10.3109/10428194.2011.631159

[25] BACHANOVA V, BURKE MJ, YOHE S, CAO Q, SANDHU $\mathrm{K}$ et al. Unrelated cord blood transplantation in adult and pediatric acute lymphoblastic leukemia: effect of minimal residual disease on relapse and survival. Biol Blood Marrow Transplant 2012; 18: 963-968. http://dx.doi.org/10.1016/ j.bbmt.2012.02.012

[26] DALY A, SAVOIE ML, GEDDES M, CHAUDHRY A, STEWART D et al. Fludarabine, Busulfan, Antithymocyte Globulin, and Total Body Irradiation for Pretransplantation Conditioning in Acute Lymphoblastic Leukemia: Excellent Outcomes in All but Older Patients with Comorbidities. Biol Blood Marrow Transplant 2012; 18: 1921-1926. http://dx.doi. org/10.1016/j.bbmt.2012.07.017

[27] BRUNSTEIN CG. Umbilical cord blood transplantation for the treatment of hematologic malignancies. Cancer Control 2011; 18: 222-236.

[28.] MICHEL G, ROCHA V, CHEVRET S, ARCESE W, CHAN KW et al. Unrelated cord blood transplantation for childhood acute myeloid leukemia: a Eurocord Group analysis. Blood 2003; 102: 4290-4297. http://dx.doi.org/10.1182/blood-200304-1288

[29.] WALL DA, CARTER SL, KERNAN NA, KAPOOR N, KAMANI NR et al. Busulfan/melphalan/antithymocyte globulin followed by unrelated donor cord blood transplantation for treatment of infant leukemia and leukemia in young children: 
the Cord Blood Transplantation study (COBLT) experience. Biol Blood Marrow Transplant 2005; 11: 637-646. http:// dx.doi.org/10.1016/j.bbmt.2005.05.003

[30] KURTZBERG J, PRASAD VK, CARTER SL, WAGNER JE, BAXTER-LOWE LA et al. Results of the Cord Blood Transplantation Study (COBLT): clinical outcomes of unrelated donor umbilical cord blood transplantation in pediatric patients with hematologic malignancies. Blood 2008; 112: 4318-4327. http://dx.doi.org/10.1182/blood-2007-06098020

[31] FRANGOUL H, WANG L, HARRELL FE JR, HO R, DOMM J. Preengraftment syndrome after unrelated cord blood transplant is a strong predictor of acute and chronic graftversus-host disease. Biol Blood Marrow Transplant 2009; 15: 1485-488. http://dx.doi.org/10.1016/j.bbmt.2009.07.001

[32] PATEL KJ, RICE RD, HAWKE R, ABBOUD M, HELLER G et al. Pre-engraftment syndrome after double-unit cord blood transplantation: a distinct syndrome not associated with acute graft-versushost disease. Biol Blood Marrow Transplant 2010; 16: 435-440. http://dx.doi.org/10.1016/j.bbmt.2009.10.022
[33] WANG X, LIU H, LI L, GENG L, DING K et al. Pre-engraftment syndrome after unrelated donor umbilical cord blood transplantation in patients with hematologic malignancies. Eur J Haematol 2012; 88: 39-45. http://dx.doi.org/10.1111/ j.1600-0609.2011.01709.x

[34] SAAVEDRA S, SANZ GF, JARQUE I, MOSCARDO F, JIMENEZ C et al. Early infections in adult patients undergoing unrelated donor cord blood transplantation. Bone Marrow Transplant 2002; 30: 937-943. http://dx.doi.org/10.1038/ sj.bmt.1703764

[35] BECK JC, WAGNER JE, DEFOR TE, BRUNSTEIN CG, SCHLEISS MR et al. Impact of cytomegalovirus (CMV) reactivation after umbilical cord blood transplantation. Biol Blood Marrow Transplant 2010; 16: 215-222. http://dx.doi. org/10.1016/j.bbmt.2009.09.019

[36] MILANO F, PERGAM SA, XIE H, LEISENRING WM, GUTMAN JA ET AL. Intensive strategy to prevent CMV disease in seropositive umbilical cord blood transplant recipients. Blood 2011 118: 5689-5696. http://dx.doi.org/10.1182/blood-2011$\underline{06-361618}$ 